\title{
GOVERNAMENTALIDADE LIBERAL NO DISCURSO SOBRE A MACONHA NA FOLHA DE S. PAULO
}

\author{
GUILHERME MALTEZ SOUZA ${ }^{1}$
}

Faculdade de Educação, Programa de Pós-graduação em Educação

Universidade Federal do Rio Grande do Sul

Av. Paulo Gama, s/nº, prédio 12.201 - 90046-900 - Porto Alegre - RS - Brasil

guilhermemaltez@gmail.com

\begin{abstract}
Resumo. Este artigo trata das formas de como a maconha foi concebida historicamente como um objeto de conhecimento e sua recente ressignificação em um campo especifico da mídia, representada pelo jornal Folha de S. Paulo. Os textos do jornal são entendidos como dispositivos pedagógicos da mídia e, a partir do discurso reproduzido na Folha, o artigo vê a operacionalização de uma racionalidade liberal, própria da governamentalidade descrita por Foucault (2008).
\end{abstract}

Palavras-chave: drogas; maconha; discurso; governamentalidade.

\begin{abstract}
This article deals with the ways in which marijuana was historically conceived as an object of knowledge and its recent signification in a specific field of the media, represented by Folha de S. Paulo newspaper. The newspaper's texts are understood as pedagogical devices of the media and, based on the discourse reproduced in Folha, the article sees the operationalization of a liberal rationality, typical of the governmentality described by Foucault (2008).
\end{abstract}

Keywords: drugs; marijuana; speech; governmentality.

\section{INTRODUÇÃO}

Este artigo é dedicado a apresentar as maneiras como historicamente a maconha foi concebida como objeto ${ }^{2}$. Se até meados do século XX a maconha esteve "solta", a partir dessa época foi "prensada" pelo discurso médico e pelo Estado e, assim, tornou-se algo sobre o qual se deve intervir ${ }^{3}$. Tal foi o esforço e o investimento para controlar o uso (e

\footnotetext{
${ }^{1}$ Doutorando em Educação na Universidade Federal do Rio Grande do Sul.

${ }^{2}$ Tal esforço encontra-se detalhado na dissertação de mestrado defendida em julho de 2017, Dispositivo pedagógico e regulação cultural no discurso antiproibicionista da maconha (SOUZA, 2017).

${ }^{3}$ Solto e prensado são duas formas usuais de denominar a maconha consumida no Brasil, sendo a primeira denominada em razão da segunda. A maconha "prensada", também conhecida como paraguaia, é a planta da maconha inteira após passar por um processo de prensa assumindo forma similar a blocos, quadrados ou retangulares, e que são divididos em partes menores para venda direta ao consumidor. A maconha solta é a que se mantém próxima à forma original da planta.
} 
usuários) da maconha, que a união entre medicina e Estado produziu no senso comum qual o tamanho e a importância da maconha dentre as outras substâncias classificadas como drogas. Não existe quem não tenha sido advertido com a famosa e intensamente repetida designação a respeito da maconha como a porta de entrada para drogas mais pesadas. A pesquisa que baseia a produção deste artigo identifica uma discursividade que procura alterar o estatuto da maconha entre as outras drogas.

O estudo é baseado em textos do jornal Folha de S. Paulo, que oferecem aos seus leitores a possibilidade de ressignificar a maconha a partir da crítica às formas como a maconha foi governada nos últimos anos e às políticas de drogas assumidas por esses governos. Esta mudança discursiva, como veremos, é baseada na crítica à razão de um Estado que tem a pretensão de governar tudo e a todos e em defesa de uma prática de governo que intervenha o mínimo possível, uma forma liberal de governar (FOUCAULT, 2008, 2008a). O objetivo do artigo consiste, portanto, em apresentar, descrever e analisar a transformação que ocorre no estatuto da maconha como objeto de discurso e quais as racionalidades que produzem a maconha enquanto objeto de um discurso. A pesquisa analisou textos editoriais da Folha (que figura entre os meios de comunicação mais acessados no Brasil), entre 2009 e 2013, a partir de consulta pelo termo "maconha" no acervo digital do jornal.

Na seção "Cotidiano", do jornal Folha de S. Paulo, em 15 de setembro de 2018, encontrase a seguinte notícia: "Ministério engaveta pesquisa de $\mathrm{R} \$ 7$ milhões sobre uso de drogas". O subtítulo informa que foram entrevistadas 17 mil pessoas e que a gestão Temer alegava problemas na metodologia da pesquisa. A mesma matéria, na versão online do jornal, possui um título que diz praticamente a mesma coisa, no entanto, com um tom mais acusatório: "Governo Temer engaveta pesquisa sobre uso de drogas que custou R\$ 7 milhões". Tanto com o "Ministério" quanto com a mudança para "Governo Temer" fica evidente o esforço de atribuir ao governo uma irresponsabilidade, afinal, o governo engavetou uma pesquisa que teve um dispêndio de 7 milhões de reais. Se o governo gastou em algo que não deveria, ou se está desperdiçando a oportunidade de dispor em uma grade analítica as práticas de milhares de brasileiros, não é menos importante do que a crítica de que o governo está agindo mal. Uma pesquisa sobre o uso de drogas ou a não conclusão da pesquisa sobre o uso de drogas tornam-se caminhos para uma crítica a um modelo de governo.

Existem temas que possuem a capacidade de transbordar as fronteiras ou as restrições de uma determinada área. Ao comentar suas impressões sobre os conteúdos de um jornal, Bruno Latour demonstra o que chamou de "proliferação dos híbridos", quando diz que, em um mesmo artigo de jornal, podemos encontrar um fio que liga reações químicas e reações políticas, "as proporções, as questões, as durações, os atores não são comparáveis e, no entanto, estão todos envolvidos na mesma história" (2013, p. 7). O que caracteriza um tema híbrido é a facilidade que torna possível transitar entre disciplinas distintas como a medicina e a antropologia cultural, entre físico-química e ciência política, entre microbiologia e economia.

Sobre as substâncias que hoje designamos drogas confluem esforços de diferentes campos do saber. Os artigos sobre as drogas em um jornal de alcance como a Folha, oferecem uma interessante superfície para analisar como se dão os embates discursivos sobre as drogas (e que produzem as drogas) enquanto objeto. Procuro demonstrar que ao falar 
sobre as drogas, mais do que falar sobre saúde, economia, cultura ou política, o jornal produz um espaço em que se enfrentam, se articulam, se aproximam ou se afastam, de acordo com o interesse, tática ou estratégia, as diferentes áreas do saber que visam agir, a partir de uma racionalidade, em uma maneira de governar, de agir sobre ações possíveis, de conduzir as condutas, como bem demonstrou Michel Foucault (2008).

$\mathrm{O}$ artigo traz os conceitos teóricos que orientaram a pesquisa realizada no âmbito do mestrado acadêmico, uma caracterização sucinta da maneira como entende a função pedagógica do jornalismo a partir das escolhas do que considera os fatos de interesse geral e ao público ao qual se destina para, por fim, trazer os textos da Folha analisados a partir da racionalidade que orienta uma governamentalidade liberal.

\section{BIOPODER, GOVERNAMENTALIDADE E DROGAS}

O poder disciplinar e a biopolítica são duas faces de um poder que age sobre a vida. $\mathrm{O}$ biopoder, que faz viver, ao contrário do poder soberano, que faz morrer. Para essa maneira de analisar a emergência de um poder sobre a vida, Foucault utiliza uma noção metodológica que chamou de governamentalidade. Esse recurso permite a Foucault analisar as maneiras do poder agir dentro da modernidade, dentro de uma racionalidade que visa a agir sobre condutas possíveis tanto no nível do indivíduo quanto da população. É aí que vai funcionar a distinção que faz entre as técnicas disciplinares que normatizam e os dispositivos de segurança que normalizam.

Foucault (2008) utilizou o conceito da governamentalidade como noção metodológica para realizar um deslocamento dentro da sua analítica do poder. O deslocamento é uma prática imanente à filosofia de Foucault e acontece em mais de um nível. Um deles seria a diferença na sua forma de analisar o poder. Não do centro do poder (inclusive desmistificando essa hipótese e demonstrando sua capilaridade), não o poder localizado, que seria uma posse do Estado, por exemplo, mas analisar o poder através das relações e das práticas entre os sujeitos. Portanto, o primeiro ponto de corte no deslocamento de Foucault em relação à analítica do poder é abandonar sua análise unicamente como repressão (poder que só age negativamente, através da força) e do poder como posse (poder transmitido por herança, que seria fonte do poder político).

Nesse processo, diversas esferas da vida se convertem em objeto da governamentalidade. Retomando, há uma incorporação das relações de poder próprias do pastorado pelas técnicas disciplinares. Através de uma espécie de aperfeiçoamento das técnicas de poder pastoral pelas disciplinas, aparecem as condições de novas formas de controle, que podem abrir mão de centrar sua força no indivíduo. É aí que as práticas de governar próprias do Estado se tornam mais detalhistas e precisas sem que o foco de suas ações sejam os indivíduos. Com o foco na população temos a estatização de formas particulares de governar os indivíduos, no sentido expressado por Foucault (2008) como ação sobre as condutas. É disso que trata a governamentalidade. Um exemplo bem explorado por Foucault foi a saúde da população. Para agir no nível da população, foi fundamental que se desenvolvesse uma prática médica que produzisse padrões de normalidade intervindo também para definir e delimitar o que estaria fora do normal. 
Sobre a analítica do poder de Foucault, de um poder soberano baseado no modelo da família e de gestão sobre a vida e a morte para um poder que faz viver e deixa morrer, de um poder soberano sobre a vida a um biopoder que produz a vida, podemos inserir algumas questões sobre as drogas. Utilizando Foucault como uma caixa de ferramenta de conceitos pertinentes para trabalhar historicamente, podemos ver as drogas compreendidas dentro de uma tecnologia que as transformaram em objeto a partir dos saberes da medicina e de uma razão de Estado. Analisar a história das drogas com esses conceitos é o que permite falarmos em genealogia da biopolítica das drogas.

É a partir de uma racionalidade governamental que as drogas viram alvo do poder, na instância do Estado. Com a finalidade de controlar determinados segmentos e garantir a segurança da população, o Estado se valeu da proeminência do saber médico como o emissor do discurso verdadeiro sobre o corpo e a vida. Sob o pressuposto da garantia moral como mantenedora da ordem, da segurança e do bom andamento das condutas populacionais, o Estado "viu" nas drogas a forma de exercer uma determinada racionalidade, que tornou possível o exercício do poder sobre as populações percebidas como desviantes, perigosas, improdutivas, entre outras denominações que designavam as parcelas visadas com determinada prática governamental. Cabe ressaltar que nesse percurso de perseguição a determinadas drogas, outras ficaram livres, evidenciando que o alvo em si não eram as drogas, mas os infames, os loucos, os doentes, e toda uma série de designações que se referem à ideia de perigo e remetem à questão da segurança de uns a partir do controle de outros. Portanto, seguindo a ferramenta analítica da governamentalidade (FOUCAULT, 2008), o Estado se valeu das drogas para exercer poder sobre os sujeitos que tiveram suas práticas transformadas em crimes e, assim, tornálos governáveis.

A perseguição às drogas (e seus usuários) inscreve-se, portanto, no contexto em que o uso de drogas passa a ser objeto de conhecimento, como destacou o trabalho de Tiago Ribeiro (2013). As "práticas de uso de drogas" se tornaram foco da racionalidade política e científica, "sendo progressivamente descritas, classificadas e submetidas a lógicas particulares de entendimento" (RIBEIRO, 2013, p. 25). A modernidade representa o período em que os saberes se constituíram enquanto "Ciência", fazendo das substâncias e "seus utilizadores objetos de um tipo peculiar de conhecimento" e os insere "em um sistema de descrições e classificações" (RIBEIRO, 2013, p. 33).

Fiore (2007) analisa o momento em que as drogas ganharam destaque por meio de intervenções públicas. A medicina social, já desfrutando de ampla legitimidade, não abriu mão de "entender a questão como sendo prioritariamente de saúde pública (FIORE, 2007, p. 28-29). A consolidação da medicina social, legitimada como saber científico, aumentou sua força institucional e política. As drogas, como destacou Fiore (2007, p. 29), "foram tomadas como tema de preocupação para autoridades médicas e sanitárias".

Se há uma proliferação discursiva em torno do tema da maconha, a mídia consiste num espaço privilegiado onde a intensificação deste discurso é possível. A ressignificação da maconha, na forma como é endereçada ao leitor, pode indicar alterações no jogo do poder em torno do sentido da maconha e do que pode ou deve ser considerado droga. Trata-se, segundo a proposta deste trabalho, da emergência de uma nova discursividade sobre a maconha. A pesquisa constata o que chama de emergência da maconha no campo 
midiático, valendo-se, sobretudo, do caso do jornalismo, representado aqui pelo jornal Folha de S. Paulo.

\section{DISCURSO E DISPOSITIVOS PEDAGÓGICOS}

Stuart Hall (1997), um dos mais proeminentes autores dos Estudos Culturais, destaca a importância da cultura como um conceito pertinente para realizar as análises sociais contemporâneas. A cultura, diz Hall (1997, p. 22), "penetra em cada recanto da vida social contemporânea, fazendo proliferar outros ambientes secundários, mediando tudo". Autoras como Fischer (2002) e Marcello (2004), tratam a mídia como dispositivo pedagógico disseminado na cultura, funcionando no interior do jogo do poder. Os veículos midiáticos se relacionam a essa proliferação dos outros espaços em que ocorre educação pois, conforme Hall (1997, p. 40-41):

o que é a educação senão o processo através do qual a sociedade incute normas, padrões e valores - em resumo, a cultura - na geração seguinte na esperança e na expectativa de que, desta forma, guiará, canalizará, influenciará e moldará as ações e crenças das gerações futuras conforme os valores e normas de seus pais e do sistema de valores predominante da sociedade? O que é isto senão regulação - regulação da moral feito pela cultura?

Fischer (2001) demonstra, a partir de Foucault, que a construção e produção discursiva do social é atravessada por relações de poder. O discurso é uma função que atravessa a linguagem e manifesta a possibilidade de sua condição de existência: "o que permitirá situar um emaranhado de enunciados numa certa organização é justamente o fato de eles pertencerem a uma certa formação discursiva". Para a autora, "estamos sempre obedecendo a um conjunto de regras" (FISCHER, 2001, p. 204) e estas regras são históricas e relacionam-se sempre com a pretensão de verdade.

Utilizando o referencial teórico de Foucault, Rosa Fischer (2002) analisa o papel da mídia como fundamental na constituição dos sujeitos e das subjetividades. A mídia, como mediadora de discursos contribui na produção dos sentidos e de significados, determinando a maneira como os argumentos efetivamente dizem respeito à realidade $\mathrm{e}$ à verdade das coisas. Tal entendimento, aproxima-se, então, da definição de dispositivo elaborada por Foucault (1985) sobre a sexualidade. Valendo-se igualmente de Stuart Hall (1997), Fischer (2002) reconhece que as atuais mudanças não podem ser entendidas fora do âmbito cultural e da crescente amplitude de alcance da informação, em escala global, mediada pelas novas tecnologias.

A mídia, além de conformar um campo próprio de saber, específico das próprias mídias e suas tecnologias, constitui-se num veículo de circulação de diversos saberes. Esses campos, discursos, saberes, dispostos pela mídia, através de imagens, sons e textos, são atravessados por lutas e disputas de poder em torno dos significados e sentidos atribuídos ao tema (como sexo, drogas, aborto, células-tronco etc.). Fischer (2001) refere que, ao lidar com discursos, não se trata de analisá-los como um conjunto de signos (elementos que remetem a conteúdos ou representações), mas como práticas que formam sistematicamente os objetos em questão. 
No primeiro volume da História da sexualidade Foucault (1985) aponta a proliferação discursiva em torno do sexo como indicativa de intensificações nas relações de poder que agem sobre o sexo. Foucault (1985, p. 53). O discurso "veicula e produz poder, reforçao, mas também o mina, expõe, debilita e permite barrá-lo" (FOUCAULT, 1985, p. 96). A sexualidade, ao invés de reprimida, é incitada o tempo todo. Dela se faz falar onde antes havia silêncio. Não que não estivesse lá, mas o dispositivo da sexualidade a transforma em um problema, que a psiquiatria toma para si e assume a voz de autoridade, detentora da verdade do sexo.

Eduardo Vargas (2008, p. 55) defende a possibilidade de "afirmar a existência de um dispositivo das drogas em sociedades como a nossa, capaz de criar o próprio fenômeno das drogas enquanto um efeito que goza do paradoxal estatuto de ser tão reprimido quanto incitado". Portanto, e como dito anteriormente, se existe esta chamada proliferação discursiva em torno do tema da maconha, a mídia consiste num espaço privilegiado onde a intensificação deste discurso é possível.

A mídia, como defendido até aqui, possui o privilégio de, a partir de um determinado discurso, contribuir na direção da produção de subjetividades. Valendo-se tanto das tecnologias e mecanismos de disciplina quanto de controle, o dispositivo pedagógico da mídia atua para produzir e reproduzir modos de pensar de acordo com uma racionalidade.

Se a educação não está restrita aos espaços escolares, um trabalho pertinente para quem pratica a análise social é investigar, descrever e apontar quais são e de onde vêm os discursos educacionais que operam fora desse espaço tradicional da escola. A mídia, como destacou Fischer (2002), possui um papel fundamental na constituição dos sujeitos. Além de mediar diferentes discursos, contribui para a construção de sentidos e significados. Esse papel é determinante para que os argumentos trazidos sejam efetivamente relacionados à realidade e à verdade das coisas. Conforme a autora, as eventuais mudanças que ocorrem sobre questões de relevante interesse público não podem ser entendidas fora de um âmbito cultural e do crescente alcance da informação.

\section{O “PAPEL" DO JORNALISMO E O LEITOR DA FOLHA}

O jornalismo consiste em uma atividade profissional que pretende alcançar e narrar a totalidade dos fatos. Diante da questão mais ampla "o que é jornalismo?", Nelson Traquina (2005, p. 19) diz que, em última instância, o jornalismo "é a vida": "um exame da maioria dos livros e manuais sobre jornalismo define as notícias em última análise como tudo o que é importante e/ou interessante. Isto inclui praticamente a vida, o mundo e o outer limits".

O jornalismo constrói uma versão do mundo através das notícias. Para falar da maneira "livre" como a conhecemos, o jornalismo atravessou uma longa história de luta e defesa pela democracia. Contra o poder absoluto, a censura e em defesa do livre mercado e da democracia: este é o jornalismo em ascensão, durante esta etapa histórica (fim do regime absolutista e emergência burguesa sob inspiração teórica do liberalismo iluminista). $\mathrm{O}$ jornal é, portanto, recorte, seleção da realidade, uma malha costurada pelas mãos de muitos jornalistas, em última instância, mas antes, pelo próprio jornal: "uma importante afirmação teórica é precisamente que os profissionais do campo jornalístico definem em 
última análise para nós as notícias e contribuem ativamente na construção da realidade" (TRAQUINA, 2005, p. 29).

O Manual da redação (2011), uma espécie de guia que "contém as normas e recomendações que norteiam o trabalho dos jornalistas da Folha", fala sobre a seletividade na escolha das pautas, que devem ser os assuntos "de incontestável interesse geral, os acontecimentos que podem modificar as estruturas políticas, econômicas e culturais de uma cidade, de um país ou do mundo" (p. 22). O interesse geral, ou interesse público, é o principal alvo do jornalismo. O objetivo da sua atividade é suprir a demanda e o anseio do interesse público pelos acontecimentos que a partir do critério do jornalista atingem a condição de notícia.

Sartor (2016) analisa a construção social do interesse público como função primeira do jornalismo e como assume um valor central no sistema que rege a atividade jornalística. A noção de interesse público, apesar de sua naturalização, é indeterminada, imprecisa e fugidia. Trata-se de uma "força discursiva e normativa que se mantém mesmo com imprecisão, sobretudo no jornalismo" e manifesta-se como critério que incide diretamente na atividade do produtor da notícia (SARTOR, 2016, p. 22). Assim, são os profissionais do jornalismo que atribuem sentidos à noção de interesse público. Storch (2012) analisa a leitura como um fenômeno de negociação de sentidos que constitui o jornalismo. Se o interesse público é construído como mostrou Sartor (2016) é preciso pensar a que tipo de leitor interessam as notícias. A leitura é realizada em função de um tipo de discurso e no caso do jornal isso se torna ainda mais acentuado pois o próprio jornalismo consiste em uma prática discursiva. A autora demonstra a que é importante conhecer os modos propostos de leitura para conhecer os leitores propostos pelos detentores da produção da notícia, "que escrevem não apenas um tipo de jornalismo, mas um tipo de mercado editorial" (STORCH, 2012, p. 16).

As práticas jornalísticas são práticas fundamentalmente discursivas. Como foi demonstrado, os discursos obedecem a determinadas regras de formação. Os discursos enunciados pela Folha de S. Paulo tornam-se materialidades do mundo social e são sustentados pelas dinâmicas de poder e por locais privilegiados de exercício da palavra.

\section{AS DROGAS E A MACONHA NA FOLHA}

De modo sintético, pode-se afirmar que a história da veiculação da maconha no Brasil atravessa um momento farmacológico (até o início do século XX), como o momento em que ela sai do "ostracismo discursivo" que emerge no discurso médico, passando pela criminalização do usuário, até o momento que foi investigado por Ribeiro (2016), chamado de resistência liberal. Essa forma de resistência apresenta-se como possível receptora do endereçamento dos textos da Folha, os quais operam, na forma como entendo neste trabalho, como mecanismos de regulação ou governo pela cultura.

O primeiro momento, reiterando a exposição anterior sobre o período histórico em que as drogas gozavam de relativa liberdade (até o século XX), é bem representado pela divulgação na mídia dos Cigarrettes Indiennes, produzidos pela Grimault \& Cie (laboratório de origem francesa). O jornal Estadão, no final do século XIX e início do 
século XX, anunciava os cigarros de Cannabis indica para tratamento de doenças ${ }^{4}$. A circulação de almanaques farmacêuticos anunciando os Cigarrettes Indiennes, produzidos pela Grimault \& Cie, ocorreram até 1938, quando se tornam mais rígidos o controle, a regulamentação e a produção de substâncias como a maconha e a cocaína (TORCATO, 2016).

O segundo momento histórico da veiculação da maconha na cultura brasileira, está vinculado ao período designado como punitivista. O jornalismo brasileiro, de modo geral, atuou (e atua) como protagonista no processo de divulgação da maconha como substância patológica, desviante e criminosa. As drogas se tornaram, durante o século XX, um dos principais alvos do que Foucault (2008) chamou de Estado de polícia, que visava agir nas condutas, com certa prerrogativa moral, para atingir o "bom governo". O indivíduo usuário de maconha, assim como outros indivíduos que ocuparam o lugar de representantes da loucura, do desemprego, da "delinquência" e do crime, em suma, todo alvo do controle, eram vistos como antagônicos ao fortalecimento e ao aumento das riquezas do Estado.

O terceiro momento é o reflexo da resistência e do princípio de autolimitação intrínseca ao Estado e refere-se à emergência das racionalidades liberais e neoliberais, no Brasil, como vimos no trabalho de Ribeiro (2016) representada também na imprensa, através dos textos do jornal Folha de S. Paulo. No referido trabalho, a análise das formas de resistência é feita a partir de um fórum virtual de usuários de maconha. Esses usuários defendem um "consumo responsável" cujo primeiro passo seria plantar a própria maconha (RIBEIRO, 2016, p. 266). Plantar a maconha, na análise de Ribeiro (2016, p. 267) funciona como "operador de responsabilidade" pessoal, social e de segurança, uma vez que afasta esses usuários do circuito criminoso do comércio de drogas. Segurança também de si mesmo, uma vez que através da defesa do cultivo próprio é veiculada também a ideia de que isso resulta em "hábitos mais saudáveis" (RIBEIRO, 2016, p. 267). A comunidade virtual em questão, na visão do autor, contém um projeto educativo e consiste em formar sujeitos que se educam para melhor governar a si mesmos.

Atualmente, o Grupo Folha detém, além da Folha de S. Paulo, o jornal Agora São Paulo, destinado às classes populares. Dois jornais, destinados a dois segmentos sociais distintos: um "qualificado" e outro popular. Sandra Goulart (2011) analisa a recorrência dos nomes das diferentes drogas nos jornais Folha e Agora. Conforme Goulart, a Folha demonstra tendência em abrir seu espaço para o debate sobre as políticas de drogas. Já o Agora, segue a tradicional abordagem de associação direta entre drogas, crime e violência. Para um mesmo tema, no caso as drogas, Goulart $(2011,2012)$ demonstra que existem duas abordagens distintas.

\footnotetext{
${ }^{4}$ De acordo com a reportagem "Maconha: de uso medicinal a caso de polícia", de 13 de abril de 2012, "o uso da maconha no Brasil é descrito nas páginas do Estadão desde o fim do século 19. Como não havia restrição à droga - só em 1938 a substância foi considerada entorpecente - e o uso medicinal era corriqueiro, havia vários anúncios patrocinados por médicos e clínicas exaltando os benefícios da cannabis em tratamentos de saúde". Disponível em http://brasil.estadao.com.br/blogs/arquivo/maconha-de-usomedicial-a-caso-de-policia/. Acesso em 10 nov. 2018.

${ }^{5}$ A Folha considera o seu leitor "ultraqualificado": "o leitor da Folha nas versões papel e digital está no topo da pirâmide social. No caso do impresso, $41 \%$ fazem parte da classe A, contra $3 \%$ na população em geral. Três quartos fizeram faculdade e $24 \%$ também a pós-graduação; no país são $13 \%$ e $2 \%$, respectivamente". Disponível em http://www1.folha.uol.com.br/paineldoleitor/2011/10/991055-leitor-dafolha-e-ultraqualificado-mostra-pesquisa.shtml. Acesso em 10 nov. 2018.
} 
Na Folha, Goulart (2012) demonstra que a existência de maior tolerância e tendência em debater as drogas é mais recorrente quando se trata da maconha. Outras drogas, como o crack, seguem sendo associadas às situações de violência e frente a elas, sendo exigidas maiores ações para reforçar o "combate ao crack". A maconha até recentemente recebeu o mesmo tratamento que outras "drogas". O que se diz sobre as drogas, em determinado contexto ou local, é reflexo da forma como a cultura em questão estabelece a relação com as drogas.

A Folha de S. Paulo faz circular e joga com os discursos que transitam na cultura, desde o referido saber das pessoas, o senso comum e os discursos "verdadeiros", aqueles organizados com pressupostos científicos. O discurso sobre a maconha na Folha, portanto, é constituído a partir de uma série de saberes e práticas e tomam forma, sobretudo, nos textos editoriais.

Os textos da Folha de S. Paulo endereçam-se não diretamente aos usuários autorreflexivos (RIBEIRO, 2016), mas utilizam-se da mesma racionalidade liberal movimentada por eles para conduzir sua crítica ao Estado de polícia que governou e governa sobre as condutas desses usuários. O jornal produz, através desses textos, um projeto educativo pautado nos princípios da racionalidade liberal.

A pesquisa contemplou um período de cinco anos, entre 2009 e 2013. A Folha de S. Paulo foi o jornal escolhido, pois é o de maior circulação, disponibiliza seu acervo de forma gratuita e é representativa de uma população que constitui alvo estratégico de uma governamentalidade liberal. O editorial, segundo o próprio Manual da Redação (2011, p. 66), é o texto que "expressa a opinião de um jornal" e

na Folha, seu estilo deve ser ao mesmo tempo enfático e equilibrado. Deve evitar o sarcasmo, a interrogação e a exclamação. Deve apresentar com concisão a questão de que vai tratar, desenvolver os argumentos que o jornal defende, refutar as opiniões opostas e concluir condensando a posição adotada pela Folha.

Portanto, na perspectiva adotada na presente pesquisa, os textos emitidos e sustentados pelo jornal, sobretudo através da posição editorial, remetem aos campos discursivos que a empresa jornalística sustenta sobre si e também ao discurso ao qual ela se filia. Para o período selecionado, foram encontrados 18 editoriais. Na pesquisa realizada no âmbito da dissertação, todos os 18 resultados foram analisados. Para fins deste artigo trago fragmentos dos editoriais que considero representativos da análise ${ }^{6}$.

\section{EDITORIAIS DA FOLHA E A GOVERNAMENTALIDADE LIBERAL}

No dia 13 de março de 2009, uma reportagem na seção "Mundo", destacou acontecimentos importantes na política internacional repercutindo o encontro dos países que integram a Comissão de Narcóticos das Nações Unidas, em Viena, onde aprovaram diretrizes consideradas bastante ambiciosas pelo editorial do dia 15 de março de 2009 . O título da reportagem 13/3/2009 ("ONU quer pôr fim a uso de drogas até 2019") demostra

${ }^{6}$ Para a descrição completa dos editoriais e análise mais aprofundada do material coletado, ver Souza (2017). 
a intenção do encontro. $\mathrm{O}$ texto destacou que a intenção dos países europeus direcionava para uma política de redução de danos, política social que pretendia pensar no usuário como alguém que precisa de tratamento médico e diminui a abordagem criminal para as políticas de drogas. Esta abordagem criminal, destacou a reportagem, que direciona a política de drogas ao método "tradicional", pressupõe o aparato policial e militar, que pretende coibir a produção e o consumo de drogas, "bancado sobretudo pelos EUA", prevaleceu no encontro da ONU.

\section{Trechos do editorial "Repressão ilusória", 15/03/2009 \\ ELIMINAR o uso de drogas no mundo até 2019? Ou, numa formulação mais prudente, "minimizá-lo" nos próximos dez anos? \\ Um objetivo a tal ponto ambicioso parece consistir, sobretudo, na maneira mais rápida de levar ao descrédito as autoridades que o formularam. \\ Trata-se de problema tão complexo e persistente que pensar em eliminá-lo num prazo de dez anos faz, no fundo, tanto sentido quanto pretender que o crime, a guerra ou o terrorismo pudessem igualmente desaparecer da face da Terra num lapso de tempo equivalente. \\ ... \\ Acredita-se mais em xerifes do que em assistentes sociais, mais em cadeias do que em centros de tratamento para os dependentes, mais em ações militares sobre as regiões produtoras do que em planos de ajuda econômica às populações envolvidas.}

O editorial "Repressão ilusória", de 15 de março de 2009 é propositivo e tensiona questões próprias da política dos países que aplicam tais diretrizes. No editorial, a Folha reconhece e afirma que eliminar o uso de drogas no mundo como proposta de política de governo só serviria para "levar ao descrédito" as autoridades responsáveis. Mesmo assumindo o lado negativo das drogas, que chamou de "impacto devastador", que acarretaria em prejuízos pessoais e sociais, admite que "não faz sentido" pensar em eliminar o "problema tão complexo" das drogas num curto período de tempo - no caso, dez anos. A Folha reitera que pensar nesses termos é pensar nas drogas como algo a ser combatido em uma guerra, prática que o editorial está condenando e anunciando como fracasso das nações. O que a Folha propõe é que os governos deixem de governar sobre as drogas, pelo menos da maneira que vêm governando desde meados do século XX.

Como demonstrou Foucault (2008a, p. 27-28) ao discutir o liberalismo, pode-se dizer que a Folha sugere aos governos que respeitem, em termos econômicos, a lei básica do mercado, de não interferência, "autolimitação da razão governamental", de não estarem presentes em aspectos que dizem respeito à vida dos indivíduos, seus desejos e a forma como estabelecem a circulação das mercadorias. Os argumentos, no final do texto, parecem não direcionar, especificamente, para uma saída de cena do governo, mas para uma outra forma de governar: assistentes sociais, ao invés de xerifes, centros de tratamento ao invés de cadeias, "planos de ajuda econômica" antes de ações militares. Há aí um direcionamento da questão das drogas para a questão de saúde pública, o que significa a sugestão de uma outra forma de governar e de dirigir as questões relacionadas às drogas.

Em outro editorial, de 31 de agosto de 2009, denominado "Além da descriminação" refere-se à possibilidade de descriminalizar o "porte de drogas para uso pessoal", sem 
criminalizar o consumidor. A prerrogativa para fomentar o debate é a formação, por parte de ex-presidentes de países do continente americano (Fernando Henrique Cardoso e Bill Clinton, por exemplo), além de outras lideranças internacionais, como o ex-secretário geral da ONU, Kofi Annan, e o escritor peruano Mario Vargas Llosa, da Comissão Latino-Americana sobre Drogas e Democracia ${ }^{7}$. Como indica o editorial a seguir, a referida comissão propõe a descriminação (ou descriminalização) da maconha e a Folha percebe esta movimentação como "caminhos para aperfeiçoamentos institucionais".

\section{Trechos do editorial "Além da descriminação", 31/08/2009 \\ INICIATIVAS de descriminar o porte de drogas para uso pessoal ganham terreno na América Latina. \\ ... \\ O debate no Brasil, impulsionado pela proposta de descriminação da maconha feita pela Comissão Latino-Americanas sobre Drogas e Democracia, ONG coliderada pelo ex-presidente Fernando Henrique Cardoso, indica caminhos para aperfeiçoamentos institucionais. \\ ... \\ Hoje esses temas têm sido tratados a partir de convenções internacionais que dão prioridade à redução da oferta e da produção, e não da demanda. \\ Excluida a hipótese da legalização, que traria efeitos provavelmente deletérios na saúde pública, não há solução simples. No Brasil, merece apoio a proposta de criar matizes nas penas de acordo com o tipo e a quantidade de droga vendida. Mas, tratando-se de fenômeno transnacional, é preciso um novo acordo global.}

Quando o texto editorial menciona o tratamento do tema das drogas "a partir de convenções internacionais que dão prioridade à redução da oferta e da produção, e não da demanda", podemos perceber a prevalência dos termos econômicos orientando o discurso. Como demonstra Foucault (2008a, p. 329), trata-se da utilização de "análises características da economia de mercado para decifrar as relações não mercantis, para decifrar fenômenos não-econômicos". Sugere, portanto, que exista, nesta racionalidade liberal, a apropriação da economia de mercado das questões que, convencionalmente, chamamos de sociais. As drogas (e a maconha) estão inseridas naquilo que pejorativamente se chama de "mercado negro", um mercado paralelo, um mercado desregulado, mas que, como o mercado convencional, objetiva o lucro, a eliminação da concorrência e a variação dos preços de acordo com as intempéries e riscos. No caso das drogas, os riscos são oriundos da produção e comercialização de algo ilegal.

Ao sugerir, ainda, que se crie "matizes nas penas de acordo com o tipo de quantidade de droga vendida", há a ideia de que umas drogas são mais toleráveis socialmente que outras, que algumas drogas estão transitando de um campo estritamente restritivo para um aceitável. Este é o caso da maconha, diferentemente da cocaína e do crack, como observou Sandra Goulart $(2011,2012)$.

\footnotetext{
${ }^{7} \mathrm{~A}$ formação desta comissão para "propor novo foco no combate às drogas" foi noticiada pela primeira vez na Folha em 12 de fevereiro de 2009. Após apresentação de seu relatório final, em 2011, em que aponta o desperdício de verbas públicas gerado pela política global de combate às drogas, empregada pelos países signatários dos acordos proibicionistas da ONU, a referida comissão passa a se chamar Comissão Global de Políticas sobre Drogas. Relatório disponível em http://www.globalcommissionondrugs.org/wpcontent/uploads/2012/03/GCDP_WaronDrugs_PT.pdf. Acesso em 10 nov. 2018.
} 
“Questão a debater", publicado em 7 de dezembro de 2010, é mais um editorial em que a "questão" da maconha é problematizada. A Folha, ao propor a discussão nesses termos, e nesta regularidade, o faz, direcionando não aos usuários, iniciantes ou iniciados, ou às vítimas da violência ocasionada pela "guerra às drogas", mas, propõe uma crítica à racionalidade política da razão de Estado, ao excesso de governo.

\section{Trechos do editorial "Questão a debater", 07/12/2010}

O governador do Rio, Sérgio Cabral, declarou à Folha a intenção de propor à presidente eleita, Dilma Rousseff, que o governo brasileiro levante nos fóruns internacionais uma discussão sobre a legalização de drogas leves.

Por drogas leves entenda-se a maconha, substância cujo uso e comércio são crescentemente tolerados em países que têm preferido transferir o problema da esfera criminal para a de saúde pública.

...

Pesquisa Datafolha de 2008 mostrou que $76 \%$ dos brasileiros são contra a liberação do consumo da maconha. A proposta de Cabral é, no entanto, oportuna e merece ser debatida. Esta Folha considera que uma flexibilização responsável e gradativa da política proibicionista deve fazer parte da estratégia de enfrentamento da questão das drogas.

A maconha como "droga leve" reforça uma ideia já presente em outros textos da Folha. Neste momento, a ideia da Folha parece apontar diretamente na intenção de interromper o excesso de governo sobre as drogas: a melhor forma de enfrentar a questão das drogas é deixar de exercer sobre ela a política proibicionista encabeçada pelo Estado de polícia.

No dia 23 de junho de 2012 a Folha escreveu o primeiro editorial sobre as movimentações no Congresso uruguaio que levariam o país a ser o primeiro a legalizar a maconha. "Legalização à uruguaia" retoma uma série de argumentos trabalhados pela Folha a fim de estabelecer-se como porta-voz da democracia e das liberdades individuais.

\section{Trechos do editorial "Legalização à uruguaia", 23/06/2012}

Provoca discussões no Uruguai e em países do continente a notícia de que o governo do presidente José Mujica prepara proposta ao Congresso de regulamentação da venda de maconha, que passaria a ser legalizada sob controle exclusivo do Estado.

...

Agora, em meio a debates sobre medidas para conter a crescente violência associada à difusão do crack, o Executivo uruguaio pretende eliminar o tráfico de maconha por meio da legalização do comércio. $O$ Estado se encarregaria de plantar, certificar e vender o produto, uma oportunidade para tributação (e para corrupção).

$\cdots$

Espera-se que essa "estatização da maconha" possa representar um golpe contra o crime organizado, além de poupar recursos na repressão a esse tipo de substância.

Nota-se que sobre a especificidade uruguaia, com o executivo uruguaio tomando a iniciativa de levar a discussão ao Congresso e se encarregando "de plantar, certificar e vender o produto", a Folha posiciona-se de forma diferente ao que vinha argumentando nos editoriais recentes a respeito da questão da maconha, mas de forma idêntica no que se refere à postura de assumir a crítica governamental à razão de Estado. A Folha não se 
contenta com a proposta uruguaia por esta se apresentar como um desdobramento da razão de Estado, com o Estado se encarregando de todas as esferas da cadeia produtiva da maconha - o que a Folha percebe como uma oportunidade para corrupção. Em seguida, o texto torna evidente a expectativa de que a medida represente "um golpe contra o crime organizado, além de poupar recursos na repressão". O resultado em termos econômicos é o que definirá a sorte do governo uruguaio nas páginas da Folha. Poupar os recursos do Estado e poupar o Estado de se exceder.

"Kit uruguaio", de 22 de outubro, é mais um que traz considerações sobre a iniciativa uruguaia de legalizar a maconha. Caracteriza que essa e outras medidas, como a descriminalização do aborto e a união civil entre pessoas do mesmo sexo eram "patrocinadas" pelo então presidente José Mujica, em alusão ao protagonismo do governo, característico da razão de Estado (FOUCAULT, 2008). A Folha destaca também que as propostas uruguaias "têm despertado a simpatia de setores liberais e de esquerda", sugerindo que se tratam de setores distintos: os liberais visualizam uma guinada rumo ao direito às liberdades individuais e a esquerda uma manifestação da força e do poder do Estado em estabelecer a ordem e a segurança tomando o controle de uma atividade marginal, ilegal e criminosa.

\section{Trecho do editorial "Kit uruguaio", de 22/10/2012 \\ Depois de tornar-se o primeiro país do Cone Sul a descriminalizar o aborto, o Uruguai poderá, em breve, aprovar leis para legalizar a maconha e oficializar a união civil entre homossexuais. \\ Essas propostas, patrocinadas pelo presidente José "Pepe" Mujica, têm despertado a simpatia de setores liberais e de esquerda, que veem na nação meridional um exemplo para a América do Sul. \\ São decisões corajosas, não há dúvida, mas é preciso atentar para as peculiaridades uruguaias antes de concluir que sirvam para todos. \\ Os vizinhos do sul possuem longa tradição secular e foram pioneiros em matéria de direitos civis. Lembre-se, a esse respeito, que o país aprovou o divórcio em 1907 e foi um dos primeiros nas Américas a conceder o voto às mulheres. \\ $\cdots$ \\ Essas características permitem ao Uruguai ser uma espécie de laboratório liberal na região. É prudente, todavia, acompanhar os desdobramentos dessas medidas, que têm aspectos problemáticos. \\ Quanto à legalização da maconha, a ideia de estatizar o plantio e a distribuição soa extravagante e precisa ser testada para que se possa formar um juízo definitivo.}

A Folha chama de corajosa a decisão do Uruguai em propor mudanças na forma de conduzir pelo próprio governo a questão das drogas e atribui às peculiaridades históricas do país vizinho a possibilidade de implementar essa experiência, pois as suas "características permitem ao Uruguai ser uma espécie de laboratório liberal". O texto é bastante direto no que se refere à crítica ao governo com base da razão de Estado, que se pretende presente o tempo todo com a finalidade de garantir a segurança e a potência da força do Estado. Mesmo se mostrando favorável à bandeira da descriminalização do aborto, a Folha condena o modo proposto pelo Uruguai de conduzir essa prática e chama de "extravagante" "a ideia de estatizar" a maconha. 
O jornal chama para si a responsabilidade de ser porta-voz das pautas que designa dentro do campo político progressista e associa a essas pautas a racionalidade do liberalismo. Esse é o papel político desempenhado pela Folha: o jornal atuando como dispositivo político-pedagógico que adota uma perspectiva economicista em nome do liberalismo para os problemas sociais.

A maconha foi transformada em pauta e o jornalismo eleva o assunto ao âmbito da política, da economia, da sociedade e da justiça. A crítica operada por este setor, no entanto, ao invés de contribuir para a desmoralização e para redução da desigualdade e do preconceito que cerca o tema, vem operando no sentido que defendo aqui de, ao ressignificar a maconha diante de um determinado público, o fazer "educando" de acordo com os princípios que caracterizam a racionalidade liberal, restringindo o debate aos leitores "ultraqualificados".

\section{CONSIDERAÇÕES}

Os discursos enunciados pela Folha de S. Paulo tornam-se materialidades do mundo social e são sustentados pelas dinâmicas de poder e por locais privilegiados de exercício da palavra. Os textos emitidos e sustentados pelo jornal, sobretudo através da posição editorial, remetem aos campos discursivos que a empresa jornalística sustenta sobre si e também ao discurso ao qual ela se filia.

Como foi visto, o discurso faz mais do que simplesmente se referir a coisas, mas molda os saberes. Os diferentes tipos de enunciados "formam um conjunto quando se referem a um único e mesmo objeto" (FOUCAULT, 2009, p. 36). A forma como a Folha de S. Paulo regularmente se refere à maconha e correlaciona este "objeto" a acontecimentos políticos, econômicos e socioculturais transformam os enunciados sobre a maconha em discurso crítico à racionalidade governamental. $O$ discurso antiproibicionista da maconha, na Folha de S. Paulo, torna o que era uma droga em um instrumento de referência aos problemas concernentes ao governo estatal.

No desenvolvimento das tecnologias de poder, Maurício Lazzarato (2008) distingue os dispositivos da disciplina e os dispositivos de segurança. Enquanto o primeiro age no corpo e limita, impede e aprisiona, o segundo deixa fazer, incita e favorece a liberdade. Há, portanto, uma ligação entre liberdade e segurança. O mecanismo do dispositivo de segurança investe na subjetividade, produzindo modos de vida em que o indivíduo é induzido a escolher e decidir a maneira como será governado. Não um poder que age diretamente sobre o corpo, mas agindo no corpo produzindo um indivíduo livre e autônomo para governar a si mesmo a partir de uma racionalidade liberal. O liberalismo é uma política de gestão da heterogeneidade e da multiplicidade e que governa os indivíduos a partir da subjetivação.

A história da proibição das drogas e a política global de enfrentamento às drogas data do século XX. Os saberes médico e científico retiraram as drogas e a maconha do campo dos acontecimentos e deram forma a um discurso que torna essas substâncias propriedade destes saberes. A razão de Estado valeu-se desse saber para ampliar sua extensão, seu funcionamento e controle da população. Se atualmente é possível observar alterações na forma de enunciar a maconha, observadas nos textos da Folha de S. Paulo, sobretudo nos 
editoriais, significa que existem movimentações em torno do sentido atribuído a essa substância e, portanto, das formas de se relacionar socialmente com elas. Essas alterações no modo de enunciar a maconha não se destinam àquelas populações outrora alvos estratégicos do controle da razão de governo estatal, da governamentalidade da razão de Estado. Destinam-se aos sujeitos que não necessariamente usam a maconha ou outras drogas, portanto.

Aos leitores da Folha é oferecido um debate político, destacando as razões sobretudo econômicas, do fracasso da razão governamental em procurar garantir a segurança da população e o bom governo proibindo a maconha. Como demonstrou Foucault (2008a) é próprio da racionalidade liberal e neoliberal que se desenvolveram durante os séculos XIX e XX transformar em aspectos econômicos aquilo que não necessariamente faz parte desse campo.

Os sujeitos são convidados a pensar, em termos de razão governamental, que a prática estatal que guiará as condutas a respeito do uso de drogas não deve ser mais aquela que estende o governo a todas as esferas da vida social. Para esses sujeitos, a maconha se transforma numa forma de reivindicar a racionalidade liberal como modo de gerir e governar o Estado, os outros e a si mesmo.

Não se trata somente da forma de governar as drogas. A Folha defende, antes de tudo, uma racionalidade política que, dentro dos seus pressupostos, entende que o uso de maconha pode ser, se não "desgovernamentalizado", pelo menos, governado de outra maneira, com uma presença menor do Estado e com mais liberdade de mercado. É da aplicação de uma grade de inteligibilidade do liberalismo que se trata, nos editoriais da Folha, quando esta assume o que a pesquisa chamou de discurso antiproibicionista da maconha.

\section{Obras Consultadas}

ALÉM da descriminação. Folha de S. Paulo, São Paulo, 31 de agosto de 2009. (Opinião, p. A2) COMISSÃO formada por ex-presidentes propõe novo foco no combate a drogas. Folha de $\mathbf{S}$. Paulo, São Paulo, 12 de fevereiro de 2009. (Cotidiano, p. C5)

KIT uruguaio. Folha de S. Paulo, São Paulo, 22 de outubro de 2012. (Opinião, p. A2)

LEGALIZAÇÃO à uruguaia. Folha de S. Paulo, São Paulo, 23 de junho de 2012. (Opinião, p. A2)

LEITE, Edmundo. Maconha: de uso medicinal a caso de polícia. Estadão, São Paulo, 13 de abril de 2012. Disponível em http://brasil.estadao.com.br/blogs/arquivo/maconha-de-uso-medicial-acaso-de-policia. Acesso em 10 nov. 2018.

LEITOR da Folha é ultraqualificado. Folha de S. Paulo, São Paulo, 16 de outubro de 2010. Disponível em https://www1.folha.uol.com.br/paineldoleitor/2011/10/991055-leitor-da-folha-eultraqualificado-mostra-pesquisa.shtml. Acesso em 11 nov. 2018.

MINISTÉRIO engaveta pesquisa de R\$ 7 mi sobre uso de drogas. Folha de S. Paulo, São Paulo, 15 de setembro de 2018. (Cotidiano, p. B1)

QUESTÃO a debater. Folha de S. Paulo, São Paulo, 7 de dezembro de 2010. (Opinião, p. A2)

REPRESSÃO ilusória. Folha de S. Paulo, São Paulo, 15 de março de 2009. (Opinião, p. A2) 


\section{REFERÊNCIAS}

FIORE, M. Uso de drogas: substâncias, sujeitos e evento. Tese. Doutorado em Ciências Sociais, Instituto de Filosofia e Ciências Humanas, Universidade Estadual de Campinas, Campinas, 2013. FIORE, M. Uso de "drogas": controvérsias médicas e debate público. Campinas: Mercado de Letras, 2007.

FISCHER, R.M.B. O dispositivo pedagógico da mídia: modos de educar na (e pela) TV. Educação e Pesquisa. Faculdade de Educação, USP, São Paulo, v. 28, n. 1, 151-162, jan./jun. 2002.

FISCHER, R.M.B. Foucault e a análise do discurso em Educação. Cadernos de Pesquisa. Fundação Carlos Chagas, São Paulo, n. 114, 197- 223, nov. 2001.

FOUCAULT, M. A arqueologia do saber. Rio de Janeiro: Forense Universitária, 2009.

FOUCAULT, M. Nascimento da biopolítica. São Paulo: Editora Martins Fontes, 2008a.

FOUCAULT, M. Segurança, Território, População. São Paulo: Martins Fontes, 2008.

FOUCAULT, M. História da sexualidade I: a vontade de saber. Rio de Janeiro: Graal, 1985.

GOULART, S. O tema das drogas e o Grupo Folha: a Folha de S. Paulo e o Agora São Paulo.

São Paulo, 2011. Disponível em http://neip.info/novo/wp-

content/uploads/2015/04/goulart drogas midia folha sp agora sp 2011.pdf. Acesso em 11

nov. 2018.

GOULART, S. O tema das drogas na mídia paulistana: o caso da Folha de S. Paulo. COMMUNICARE: Revista de Pesquisa, Centro Interdisciplinar de Pesquisa, Faculdade Cásper Líbero, São Paulo, v. 12, $\mathrm{n}^{\circ}, 61-86,2012$.

HALL, S. A centralidade da cultura: notas sobre as revoluções culturais do nosso tempo. Educação \& Realidade, Faculdade de Educação, UFRGS, Porto Alegre, v. 22, nº 2, 15-46, jul./dez. 1997.

LATOUR, Bruno. Jamais fomos modernos. São Paulo: Editora 34, 2013.

LAZZARATO, M. Biopolítica/bioeconomia. Em: PASSOS, I.C.F. Poder, normalização e violência. Incursões foucaultianas para a atualidade. Belo Horizonte: Autêntica, 2008. p. 41-52. MANUAL da redação. Folha de S. Paulo. 17 ed. São Paulo: Publifolha, 2011.

MARCELLO, Fabiana de Amorim. O conceito de dispositivo em Foucault: mídia e produção agonística de sujeitos maternos. Educação \& Realidade, Faculdade de Educação, UFRGS, Porto Alegre, v. 29, n.1, 199-213, 2004.

RIBEIRO, Tiago M. Governo ético-político de usuários de maconha. Curitiba: Prismas, 2016. RIBEIRO, Tiago M. Do você não pode ao você não quer: uma história da prevenção às drogas na educação. Curitiba: Editora Prismas, 2013.

SARTOR, B.A. A noção de interesse público no jornalismo. Tese. Doutorado em Comunicação e Informação, Faculdade de Biblioteconomia e Comunicação, UFRGS, Porto Alegre, RS, 2016.

SOUZA, G.M. Dispositivo pedagógico e regulação cultural no discurso antiproibicionista da maconha: análise no jornal Folha de S. Paulo entre 2009 e 2013. Dissertação. Mestrado em Educação, UFRGS, Porto Alegre, 2017.

STORCH, Laura. O leitor imaginado no jornalismo de revista: uma proposta metodológica. Tese. Doutorado em Comunicação e Informação, UFRGS, Porto Alegre, RS, 2012.

TRAQUINA, Nelson. Teorias do Jornalismo. Volume 1: porque as notícias são como são. Florianópolis: Insular, 2005.

TORCATO, C.E.M. A história das drogas e a sua proibição no Brasil da Colônia à República. Tese. Doutorado em História Social, Faculdade de Filosofia Letras e Ciências Humanas, Universidade Estadual de São Paulo, São Paulo, 2016.

VARGAS, E.V. Fármacos e outros objetos sociotécnicos. Em: LABATE, B.C. et. al. (Orgs.). Drogas e Cultura: novas perspectivas. Salvador: EDUFBA, 2008. pp. 105-120. 
Artigo recebido em: nov. de 2018.

Aprovado e revisado em: abril de 2019.

Publicado em: dezembro de 2019.

Para citar este texto:

SOUZA, Guilherme Maltez. Governamentalidade liberal no discurso sobre a maconha na Folha de S. Paulo. Entremeios [Revista de Estudos do Discurso, ISSN 2179-3514, on-line, www.entremeios.inf.br], Seção Estudos, Programa de Pós-Graduação em Ciências da Linguagem (PPGCL), Universidade do Vale do Sapucaí (UNIVÁS), Pouso Alegre (MG), vol. 18, p. 123-139, jan. - jun. 2019.

DOI: http://dx.doi.org/10.20337/ISSN2179-3514revistaENTREMEIOSvol18pagina123a139 